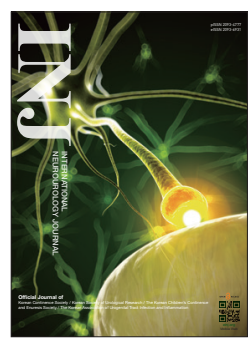

\title{
Innovative Distribution Priorities for the Medical Devices Industry in the Fourth Industrial Revolution
}

\author{
Munjae Lee ${ }^{1}$, Yeup Yoon ${ }^{1,2}$, Gyu Ha Ryu ${ }^{1,3}$, Hae Sook Bok ${ }^{4}$, Kichan Yoon ${ }^{5}$, Sewon Park ${ }^{1}$, Kyu-Sung Lee ${ }^{1,6}$ \\ ${ }^{1}$ Department of Medical Device Management and Research, SAIHST, Sungkyunkwan University, Seoul, Korea \\ ${ }^{2}$ Institute for Refractory Cancer Research, Research institute for Future Medicine, Samsung Medical Center, Seoul, Korea \\ ${ }^{3}$ Office of R\&D Strategy \& Planning, Samsung Medical Center, Seoul, Korea \\ ${ }^{4}$ Clinical Research Institute A-CRO Team, Research center for Future Medicine, Samsung Medical Center, Seoul, Korea \\ ${ }^{5}$ Research Center, Social Security Information Service, Seoul, Korea \\ ${ }^{6}$ Department of Urology, Samsung Medical Center, Sungkyunkwan University School of Medicine, Seoul, Korea
}

Purpose: This study aimed to set priorities for improving the medical device distribution structure and to suggest an innovative improvement plan for the distribution structure using the analytic hierarchy process (AHP) method, focusing on stakeholders in the medical device industry.

Methods: This study conducted a survey with 35 specialists using the AHP method, which is a multiple-criteria decisionmaking methodology, in order to set priorities for improvement plans to address the problems faced by the medical device distribution structure.

Results: The AHP analysis showed that supply stability was the most important factor, followed by greater transparency, efficiency, smart supply, and cost reduction.

Conclusions: It is necessary to establish a stable supply system and manage crises through supply stability, as well as to provide opportunities for fair trade through greater transparency. As steps towards those goals, we propose establishing a unique device identification system, an information disclosure system, online distribution, and a group purchasing organization system in Korea.

Keywords: Medical device industry; Analytic hierarchy process; Unique device identification; Group purchasing organization; Online distribution

- Fund/Grant Support: This research was supported by a grant of the Korea Health Technology R\&D Project through the Korea Health Industry Development Institute (KHIDI) funded by the Ministry of Health \& Welfare, Republic of Korea (grant number: HI14C3229).

- Conflict of Interest: No potential conflict of interest relevant to this article was reported.

\section{INTRODUCTION}

Recently, evidence-based healthcare has been transformed into precision medicine using artificial intelligence as part of the fourth industrial revolution. Accordingly, with the development of advanced medical devices and the emergence of telemedi- cine using the Internet of Things (IoT), personal information about individuals' physical bodies and health has become linked to the promotion of national health, thereby promoting the development of the medical device industry [1].

The medical device industry is part of the healthcare industry and aims to improve the quality of human life by using

Corresponding author: Kyu-Sung Lee (iD https://orcid.org/0000-0003-0891-2488 Department of Urology, Samsung Medical Center, Sungkyunkwan University School of Medicine, 81 Irwon-ro, Gangnam-gu, Seoul 06351, Korea E-mail: ksleedr@skku.edu / Tel: +82-2-3410-3554 / Fax: +82-2-3410-3027 Submitted: July 5, 2018 / Accepted after revision: July 13, 2018 
medical devices. The process of medical device distribution is managed throughout its entire cycle [2]. Medical devices are assessed for safety and efficacy. Their safety and efficacy are reviewed by the Korea Food and Drug Administration based on technical document review and clinical trial data [3]. For patients to use licensed medical devices, such devices are priced according to government policies [4]. Compared to the flexible pricing in other industries, the pricing in the medical device industry is not flexible. In the case of medical equipment, the distribution structures of high-priced and low-end medical equipment differ due to the quality of the products, and purchasing is performed offline rather than online, which is different from the distribution structure of other industries. Finally, the medical device industry also needs to constantly monitor false advertisements in order to protect consumers through the preliminary advertisement deliberation system.

Medical devices directly or indirectly affect the human body and have potential risks; therefore, quality control is very important at all stages of the process, from manufacturing and import to final consumption. However, the management standards for medical device distribution are inadequate, and the standards of medical device storage facilities and the technological management of medical devices are poor [5]. Furthermore, as flow management takes up $40 \%$ of hospitals' operating budget, efficient management of the hospital distribution network is highly important, and user-friendly distribution provides better services for customers, thereby affecting hospital profits [6]. In our aging society, the supply and costs of medical services are becoming a major social burden. Managerial improvements through cost reductions have become a crucial issue due to the constant financial challenges faced by the medical field, which require innovative improvement plans for the distribution structure of medical devices [7].

The system of direct contract and supply between medical institutions and medical product suppliers is changing into a system of collective agency for purchasing and logistic services. However, the medical device distribution structure in Korea is very complicated, and unclear distribution procedures due to the lack of a management system remains common. Currently, the medical device distribution structure in Korea takes many forms, including third-party consignment sales through various agents such as those with the sole rights for domestic distribution, branch and local dealers, and agents in deposited consignment sales who sign an agreement with another indirect supplier or purchasing agent, also known as a group purchasing organiza- tion (GPO), pay a certain amount of commission, and supply the products to hospitals through the indirect supplier. Putting GPOs in charge would make the distribution structure more transparent and fair, which is why many countries, including the United States, have systemized GPOs and legalized the contract method and price structures. Currently, Korea also has something similar to the GPO system in terms of physical operation, but there are still inadequacies in systemization, such as transparent purchase agreements and fair supply chain relations, which are key elements of the GPO system [8]. As such, since the distribution process is complicated, the stakeholders in the entire cycle of medical device distribution, such as suppliers (manufacturers and importers), distributors (agents), indirect suppliers, and hospitals, face difficulties in managing safety-related information such as distribution information, tracking, and recall of medical devices due to the disunified management system [9]. Furthermore, an unclear system for the distribution of medical devices leads to price increases, adding to the burden of patients and diminishing the soundness of health insurance [8].

Information and communication technology (ICT) methods, such as artificial intelligence, big data, and providing the products consumers need in the right place at the right time, are expanding. Thus, medical device distributors predict that the fourth industrial revolution will increase productivity in the medical device industry and bring changes to the distribution structure [10]. Such changes in the medical device industry have made it difficult for companies to survive in the market with the conventional management styles of the past [11]. A distribution structure with a competitive edge brings innovation to production, saves costs, and accelerates time to market [12]. Moreover, the development of ICT promotes the stability of the distribution environment by guaranteeing continued customer service and supply, thereby enabling efficient operation and constant process management [13]. Improving the distribution structure not only leads to inventory control, but also promotes relationships with suppliers and improves patient satisfaction [14].

Therefore, this study aimed to set priorities for improving the medical device distribution structure and to suggest an innovative improvement plan for the distribution structure using the analytic hierarchy process (AHP) method, focusing on stakeholders in the medical device industry [15]. To this end, an improvement plan was developed based on previous studies on GPOs of medical devices and on the fourth industrial revolution and supply chain. Additionally, an AHP analysis was conducted with medical device specialists to set priorities for im- 
proving the medical device distribution structure [16].

\section{MATERIALS AND METHODS}

This study conducted an AHP analysis to set priorities for improving the medical device distribution structure and to present innovative improvement plans the distribution structure. To this end, an AHP survey was conducted among specialists in various fields, including those working in public institutions, private enterprises, hospitals, and academia, and based on the survey results, priorities for policy measures were derived to respond to changes in the medical device distribution structure due to the fourth industrial revolution [17]. The top 5 evaluation items were confirmed through previous studies and brainstorming related to the distribution structure. The objective was to obtain a weighting of priorities for improving the medical device distribution structure at the top level. In this study, as shown in Table 1, there were 2 levels. Level 1 consisted of 5 high-level goals based on previous studies and brainstorming (cost reduction, higher transparency, smart supply, supply stability, and efficiency).

Moreover, this study generated a total of 16 subitems for evaluation as components of improvement plans based on the high-level goals. In a study of plans to implement GPOs for medical devices in Korea, Kim [7] claimed that advanced GPOs

Table 1. Distribution structure improvement evaluation items

\begin{tabular}{ll}
\hline Top item & \\
\hline Cost reduction & Costs related to purchasing medical devices \\
Higher transparency & Providing illegal rebates due to lack of objective information when delivering medical devices \\
Smart supply & Prepared for the fourth industrial revolution based on information technology and big data \\
Supply stability & Can supply appropriate amount to changeable situation \\
Efficiency & Streamline distribution structure with fast purchasing process \\
\hline
\end{tabular}

Table 2. Selected point for medical device distribution structure improvement plan

\begin{tabular}{|c|c|}
\hline $\begin{array}{l}\text { Factors selected for medical device distribution } \\
\text { structure improvement plans }\end{array}$ & Selection criteria \\
\hline \multicolumn{2}{|l|}{ Cost reduction } \\
\hline Medical cost reduction & Medical institution management efficiency \\
\hline Purchase unit price discount & Must provide high discount rates \\
\hline Social costs & Easing the burden of medical expenses by reducing medical device costs \\
\hline Marketing costs & Reducing marketing costs through e-commerce system \\
\hline \multicolumn{2}{|l|}{ Higher transparency } \\
\hline Giving opportunities for fair trade & Increasing purchase competitiveness by comparing information of medical institutions \\
\hline Information standardization & Disclosing objective information about goods and prices \\
\hline Rebate regulations & $\begin{array}{l}\text { Regulating hospitals and wholesale dealers taking advantage of the loophole in real transaction } \\
\text { price redemption system }\end{array}$ \\
\hline \multicolumn{2}{|l|}{ Smart supply } \\
\hline Internet-based ICT solution & Purchase/logistics/inventory control of medical devices \\
\hline Automated information & Securing flexibility of supply system \\
\hline Supply chain management & Integrating distribution network of medical devices \\
\hline \multicolumn{2}{|l|}{ Supply stability } \\
\hline Crisis management & Suitable measures of medical environment \\
\hline Stable supply system & Timely supply of medical devices as decided \\
\hline Speed & Increasing satisfaction by promptly providing medical devices \\
\hline \multicolumn{2}{|l|}{ Efficiency } \\
\hline Inventory control & Logistics and inventory control with standardized process \\
\hline Delivery system & Promoting efficiency by simplifying the distribution structure \\
\hline Real-time small purchase & Small and real-time purchases through e-procurement \\
\hline
\end{tabular}

ICT, information and communication technology. 
could increase purchasing competitiveness and efficiency based on comparative data shared among medical institutions through an e-commerce system. Furthermore, Kim [7] emphasized the need for the establishment of advanced GPOs in Korea to reduce social costs in the market through business-tobusiness e-commerce of medical supplies, such as through fair trade opportunities for supplies and the reduction of marketing costs. Based on the high-level goals presented above, this study selected sub-items to determine whether it is necessary to implement advanced GPOs to improve the medical device distribution structure in Korea, and if so, which items are relevant. $\mathrm{Ha}$ [11] used an AHP analysis to enhance efficiency related to hospital logistics by improving the method of purchasing medical consumables. Ha [11] claimed that it is first necessary to establish the infrastructure, stabilize the supply, and reduce managerial costs to simplify the method of purchasing medical consumables, which is currently a complicated process. This study considered supply stability as a high-level goal to prepare for crises and changes in the medical environment due to the rapid turnover in the supply of medical devices and the fourth industrial revolution. Shin [18] explained the concept of a smart supply chain as an alternative to reduce the complexity and uncertainty of the supply chain. An AHP analysis was conducted in which 4 categories were developed for the implementation of a smart supply chain: integration of the supply chain, establishment of a big data analytical system, rearrangement of the ICT infrastructure, and automation. The fourth industrial revolution, represented by technology such as big data, artificial intelligence, robotics, and the IoT, is expected to bring remarkable changes to logistics management. Considering its ICT infrastructure, technological level, and specialized human resources, Korea has a competitive advantage in implementing and developing the technology of the fourth industrial revolution. The medical device distribution structure is also expected to undergo major changes due to the fourth industrial revolution, and automating information processing by implementing a smart supply chain seems to be a necessary step [19].

The subitems for evaluation were selected through brainstorming about factors identified in previous studies. Table 2 summarizes the 5 high-level goals and factors that could be targeted for improvement to work towards those goals (i.e., the 16 subitems for evaluation).

This study presented the final high-level goals in level 1, and developed a structure that included a total of 3 levels, extending down to the subitems, as part of the research model.
As such, the AHP questionnaire consisted of detailed improvement plans for cost reduction, higher transparency, smart supply, supply stability, and efficiency. A total of 35 specialists working in public institutions, private enterprises, hospitals, and academia prioritized targets for improvement based on the 5 high-level goals [17].

Data were analyzed using DRESS ver. 1.7, a dedicated AHP solution. DRESS is based on the method proposed by Satty, who first presented AHP analysis. Through a survey, many evaluators can easily and quickly analyze and report a large amount of data obtained by a pairwise comparison between attributes.

\section{RESULTS}

In this study, an analysis using the weight distribution method was conducted to set priorities for improvement plans. Accordingly, this study formed a pairwise comparison matrix by judging all factors that formed the model one-by-one and established the relative order of priority by calculating the eigenvalue of the matrix. In general, pairwise comparisons were made using a 9-point scale. The relative weight among elements was then estimated, and the consistency ratio (CR) was calculated to measure the reliability of the respondents. Generally, responses are considered to have rational consistency when the CR is 0.1 or below. For the AHP survey conducted in this study, the CR of the results of each respondent was within the base value of 0.1 , thereby indicating that the results had logical consistency and validity. The specific results of the analysis are as follows [17].

\section{Importance of Improvement Plans for the Medical Device Distribution Structure by High-Level Goal}

Table 3 shows the results for the order of importance and priority of medical device improvement measures based on the 4-level improvement plans for the medical device distribution

Table 3. Medical device improvement plan relative importance and priority

\begin{tabular}{lccc}
\hline Top item (level 1) & Importance (A) & CR & Ranking \\
\hline Cost reduction & 0.12 & & 5 \\
Higher transparency & 0.21 & & 2 \\
Smart supply & 0.14 & 0.01 & 4 \\
Supply stability & 0.32 & & 1 \\
Efficiency & 0.20 & & 3 \\
\hline
\end{tabular}

$\mathrm{CR}$, consistency ratio. 
structure; that is, cost reduction, greater transparency, smart supply, supply stability, and efficiency.

As shown in Table 3 , supply stability $(0.32)$ was considered to be the most important factor for improving the medical device distribution structure, followed by greater transparency $(0.21)$, efficiency (0.20), smart supply (0.14), and cost reduction (0.12).
This indicates that specialists thought that it was important to deal with supply stability to improve the distribution structure.

\section{Importance of the Subitems of the Improvement Plans for the Medical Device Distribution Structure}

As shown in Table 4, the most important subitem within the

Table 4. Medical device improvement plan subitems relative importance and priority

\begin{tabular}{|c|c|c|c|c|}
\hline \multirow{2}{*}{ Top item (level 1) } & \multirow{2}{*}{ Subitem (level 2) } & \multicolumn{3}{|c|}{ Each factor } \\
\hline & & Importance (B) & CR & Ranking \\
\hline \multirow[t]{4}{*}{ Cost reduction } & Medical cost reduction & 0.38 & 0.01 & 1 \\
\hline & Purchase unit price discount & 0.22 & & 3 \\
\hline & Social costs & 0.24 & & 2 \\
\hline & Marketing costs & 0.16 & & 4 \\
\hline \multirow[t]{3}{*}{ Higher transparency } & Giving opportunities for fair trade & 0.43 & 0.01 & 1 \\
\hline & Information standardization & 0.23 & & 3 \\
\hline & Rebate regulations & 0.35 & & 2 \\
\hline \multirow[t]{3}{*}{ Smart supply } & Internet-based ICT solution & 0.34 & 0.01 & 2 \\
\hline & Automated information & 0.36 & & 1 \\
\hline & Supply chain management & 0.31 & & 3 \\
\hline \multirow[t]{3}{*}{ Supply stability } & Crisis management & 0.30 & 0.01 & 2 \\
\hline & Stable supply system & 0.49 & & 1 \\
\hline & Speed & 0.20 & & 3 \\
\hline \multirow[t]{3}{*}{ Efficiency } & Inventory control & 0.40 & 0.01 & 1 \\
\hline & Delivery system & 0.40 & & 1 \\
\hline & Real-time small purchase & 0.20 & & 3 \\
\hline
\end{tabular}

$\mathrm{CR}$, consistency ratio; ICT, information and communication technology.

Table 5. Sixteen priorities for improvement plan for the medical device

\begin{tabular}{|c|c|c|c|c|c|}
\hline \multirow[b]{2}{*}{ Top item (level 1) } & \multirow[b]{2}{*}{ Importance (A) } & \multirow[b]{2}{*}{ Subitem (level 2) } & \multirow[b]{2}{*}{ Importance (B) } & \multicolumn{2}{|c|}{ Total importance } \\
\hline & & & & $\begin{array}{l}\text { Total importance } \\
\qquad(\mathrm{A} \times \mathrm{B})\end{array}$ & Ranking \\
\hline \multirow[t]{4}{*}{ Cost reduction } & 0.12 & Medical cost reduction & 0.38 & 0.046 & 11 \\
\hline & & Purchase unit price discount & 0.22 & 0.026 & 15 \\
\hline & & Social costs & 0.24 & 0.029 & 14 \\
\hline & & Marketing costs & 0.16 & 0.019 & 16 \\
\hline \multirow[t]{3}{*}{ Higher transparency } & 0.21 & Giving opportunities for fair trade & 0.43 & 0.090 & 3 \\
\hline & & Information standardization & 0.23 & 0.048 & 9 \\
\hline & & Rebate regulations & 0.35 & 0.074 & 6 \\
\hline \multirow[t]{3}{*}{ Smart supply } & 0.14 & Internet-based ICT solution & 0.34 & 0.048 & 9 \\
\hline & & Automated information & 0.36 & 0.050 & 8 \\
\hline & & Supply chain management & 0.31 & 0.043 & 12 \\
\hline \multirow[t]{3}{*}{ Supply stability } & 0.32 & Crisis management & 0.30 & 0.100 & 2 \\
\hline & & Stable supply system & 0.49 & 0.157 & 1 \\
\hline & & Speed & 0.20 & 0.064 & 7 \\
\hline \multirow[t]{3}{*}{ Efficiency } & 0.20 & Inventory control & 0.40 & 0.080 & 4 \\
\hline & & Delivery system & 0.40 & 0.080 & 4 \\
\hline & & Real-time small purchase & 0.20 & 0.040 & 13 \\
\hline
\end{tabular}

ICT, information and communication technology. 
category of cost reduction was medical cost reduction (0.38), followed by the social cost reduction (0.24), purchase unit price discounts (0.22), and marketing cost reduction (0.16). The most important subitem in the category of greater transparency was giving opportunities for fair trade (0.43), followed by rebate regulations (0.35) and information standardization (0.23). The most important subitem in the category of smart supply was automated information (0.36), followed by internet-based ICT solutions (0.34) and supply chain integration (0.31). The most important subitem in the supply stability category was a stable supply system ( 0.49$)$, followed by crisis management $(0.30)$ and speed (0.20). The most important sub-item in the category of efficiency was inventory control ( 0.40$)$, followed by the delivery system (0.40) and real-time small purchases (0.20).

\section{Overall Importance of the Items of the Improvement Plans for the Medical Device Distribution Structure}

After combining the opinions of 35 specialists who participated in the decision-making process, the results of the overall order of priority for the 16 subitems of the improvement plans for the medical device distribution structure are shown in Table 5.

The most important high-level goal for improving the medical device distribution structure was supply stability, followed by greater transparency, efficiency, smart supply, and cost reduction. Integrating this finding with the prioritization of the 16 subitems, the factor that must first be considered for improving the medical device distribution structure is a stable supply system, followed by crisis management, giving opportunities for fair trade, inventory control, and the delivery system.

\section{DISCUSSION}

As part of the trend of wellness, the global medical device industry is rapidly developing as the healthcare paradigm has shifted from treatment to prevention [20]. Moreover, as a result of population aging, the supply and costs of medical services have become a major social burden. To reduce the social burden on the limited number of medical facilities and specialists, there is an increasing need for advanced medical devices for the early diagnosis of diseases and minimally invasive treatment, as well as ICT-convergence medical devices useful for home healthcare and self-healthcare [3]. However, the distribution system has continued to be unclear despite the dual penalty system for illegal rebates, due to the lack of a suitable management system and difficulties in determining the distribution flow. This has led to negative impacts on the management efficiency of medical institutions and the financial efficiency of national health insurance [2].

Thus, this study conducted a survey of 35 specialists using the AHP method, which is a multiple-criteria decision-making methodology, in order to set priorities for improvement plans to address the problems faced by the medical device distribution structure. The AHP analysis showed that supply stability was the most important factor, followed by greater transparency, efficiency, smart supply, and cost reduction. This study developed specific improvement plans based on these results.

First, it is necessary to implement a unique device identification (UDI) system for supply safety in medical device distribution. The distribution process of medical devices in Korea does not have a unified code system to manage the devices, making it difficult to manage distribution information, tracking, or safety information such as recalls. Specifically, the code system related to manufacturing and import licensing managed by the Ministry of Food and Drug Safety is different from the health insurance code system of materials for medical treatment managed by the Health Insurance Review and Assessment Service, which makes tracking management and recall handling difficult if stability issues arise, such as side effects of medical devices. Therefore, it is necessary to implement a UDI system so that medical device suppliers have codes for each unit of the product to report to the government, and to establish a unified system for suppliers, agencies, indirect suppliers, medical institutions, and government agencies to share this database [9].

Second, an information disclosure system must be implemented for medical devices to ensure greater transparency of medical device distribution, so that information about the distribution industry and market prices would be disclosed openly. A task force should be established to verify the real transaction prices of medical devices, as well as a center to report wrongful acts in distributing medical devices in order to contribute to fair trade in medical device distribution. Furthermore, the transparency of distribution pricing must be increased by verifying the import cost of high-priced medical devices that are predominantly imported. In particular, it is necessary to establish an institutional strategy to promote the proper functioning of the Korean medical device distribution market by implementing a specialized wholesale system for medical devices through tighter qualifications for medical device sellers who directly sell to end users, as occurs for home medical equipment [21].

Third, it is necessary to establish a GPO system, which is an 
advanced form of purchasing agency, in order to ensure the efficiency of medical device distribution [22]. The advanced form of GPOs not only can perform the role of purchasing, but can also deal with logistics and inventory control through ICTbased solutions software, thereby promoting efficient purchase/ logistics/inventory management and leading to cost reduction, fairness, and greater transparency of purchasing. In a specialized GPO system, certain parts of the medical device purchasing process, which had previously only involved interactions between medical institutions and suppliers, are transferred to a purchasing agent through outsourcing, thereby saving costs for medical institutions and resulting in management efficiency [23]. Moreover, medical institutions receive technical advice about medical devices, performance evaluation compared to product costs, and supplier competency data, facilitating the provision of high-quality medical services. Medical institutions can save approximately $10 \%-15 \%$ of the amount spent on purchasing medical devices and materials for medical treatment in general by using GPOs. For medical device distribution with greater volume and quantity than medicine and medical supplies, the importance and costs of logistics services are increasing. Thus, there are cases in which a new model is formed by implementing a separate company specialized in logistics services for the specialized GPO model. Furthermore, ICT can be used to establish databases at hospitals, which can be linked to hospitals to make hospital affairs more efficient. Doing so improves hospital management and integrates the in-house enterprise resource planning system of hospitals, through which many tasks can be performed, such as inventory control and financial management [7]. An advanced GPO system will enable companies to provide specialized logistics services, including purchase and inventory control, in a way that promotes transparency and efficiency in medical device distribution, which will have a positive effect on resolving the imbalance issue of medical device supply and building mutual trust [8].

The results of this study imply that in order to improve the medical device distribution structure, it is necessary to establish a stable supply system and to manage crises through supply stability, as well as to provide opportunities for fair trade through greater transparency. Therefore, stable implementation of the UDI system in Korea is needed to build a distribution information system and to improve the medical device distribution structure. This will ensure the efficiency and stability of medical device supply through the use of a single code system that unifies item classifications and standard codes. Moreover, for greater transparency, the prices of medical devices must be openly disclosed. There will be fair trade among companies when market prices are accurately reflected on the medical charges of health insurance. Finally, an advanced GPO system must be established to improve the medical device distribution structure. However, even though GPOs have been used in Korea since 2000, some public hospitals still insist on purchasing devices themselves. To resolve this issue and to establish an advanced GPO system, it is necessary to change the perceptions of hospitals and to convince them that GPOs will increase fairness, promote transparency, and provide optimum ICT-based solutions for purchasing, logistics, and inventory control in various hospital environments [24]. However, the most important matter is to clearly perceive the difference between the Korean indirect-supplier system and advanced GPOs, and to provide support for improvements of the system based on governmental investigations [8]. Furthermore, a new social consensus on the online distribution of medical devices is needed. This will lead to the entry of technologically innovative products into the market and benefit the nation by reducing distribution costs.

\section{AUTHOR CONTRIBUTION STATEMENT}

- Full access to all the data in the study and takes responsibility for the integrity of the data and the accuracy of the data analysis: $M L$

- Study concept and design: $M L, S P, K Y$

- Acquisition of data: $M L, G H R, S P$

- Analysis and interpretation of data: $M L, S P, K Y$

- Drafting of the manuscript: $M L, S P, K Y$

- Critical revision of the manuscript for important intellectual content: KSL, ML, SP

- Statistical analysis: $M L, S P, K Y$

- Obtained funding: $K S L$

- Administrative, technical, or material support: YY, HSB

- Study supervision: KSL, $M L$

\section{REFERENCES}

1. Kim JY. Regulations and government legislations issues for Internet of Things. Inst Law Sci Technol 2018;24:43-92.

2. Park HS. A study on the ways to improve regulations on rebate in the medical device industry [master's thesis]. Seoul (Korea): Dongguk University; 2015.

3. Park JY. Outsourcing practices in medical device industry [master's 
thesis]. Seoul (Korea): Sungkyunkwan University; 2018.

4. Lee M, Yoon K, Lee CH, Lee HS, Choi M. Medical device marketing strategy. Seoul (Korea): Soomoonsa; 2017.

5. Baek MJ. QR code system application for medical devices distribution career management system [master's thesis]. Seoul (Korea): Hanyang University; 2015.

6. McKone-Sweet KE, Hamilton P, Willis SB. The ailing healthcare supply chain: a prescription for change. J Supply Chain Manag 2005;41:4-17.

7. Kim MH. A study on the improvement of using GPO (group purchasing organization) for medical equipment in Korea. Seoul (Korea): Sungkyunkwan University; 2016.

8. Ji KD. A study on group purchasing organization and relationship in medical devices supply channel [master's thesis]. Seoul (Korea): Chung-Ang University; 2018.

9. Seounng HL. A study on the support methods for medical device companies for UDI introduction in South Korea [master's thesis]. Seoul (Korea): Dongguk University; 2017.

10. Jeon HY. Changes in distribution industry in the fourth industrial revolution. VIP Report 2017;710:1-15.

11. Ha JW. The selection of purchasing method for medical supplies using the AHP [master's thesis]. Seoul (Korea): Seokyeong University; 2011.

12. Li S, Ragu-Nathan B, Ragu-Nathan TS, Subba Rao S. The impact of supply chain management practices on competitive advantage and organizational performance. Omega 2006;34:107-24.

13. Soosay CA, Hyland PW, Ferrer M. Supply chain collaboration: capabilities for continuous innovation. Supply Chain Manag: Int J 2008;13:160-9.
14. Pan ZX, Pokharel S. Logistics in hospitals: a case study of some Singapore hospitals. Leadersh Health Serv (Bradf Engl) 2007; 20:195-207.

15. Handfield R, Walton SV, Sroufe R, Melnyk SA. Applying environmental criteria to supplier assessment: a study in the application of the analytical hierarchy process. Eur J Op Res 2001;141:70-87.

16. Tang C. Robust strategies for mitigating supply chain disruptions. Int J Logist 2006;9:33-45.

17. Lyu HS, Kim ES, Lee SY. An empirical study on AI risk policies via AHP survey. Legis Policy Stud 2017;9:55-81.

18. Shin JC. A study on priority of smart supply chain implementation using analytical hierarchy process (AHP) approach [master's thesis]. Incheon (Korea): Incheon National University; 2017.

19. Lee CB, Noh JH, Kim JH. A study on the perception of the impact of fourth industrial revolution on the performance of logistics management. Korea Logist Rev 2017;27:1-12.

20. Shin MH, Lee HH. International competitiveness and trade pattern of medical device industry of China, Japan and Korea. Korea Trade Rev 2011:36:25-56.

21. Lee JS. A study on the medical equipment industry's distribution activation method in Korea [master's thesis]. Busan (Korea): DongEui University; 2016.

22. Carter CR, Crum M, Liane Easton P. Sustainable supply chain management: evolution and future directions. Int J Phys Distrib Logist Manag 2011;41:46-62.

23. Hu Q, Schwarz LB. Controversial role of GPOs in healthcare-product supply chains. Prod Op Manag 2011;20:1-15.

24. Szozda N. Industry 4.0 and its impact on the functioning of supply chains. Logforum 2017;13:401-14. 